\title{
A system for restoring production energy management after emergencies
}

\author{
A. Platonov \\ Department of Economy and Management in Construction \\ and Realty Market, Ural Federal University, Russia
}

\begin{abstract}
Almost a third of Russia's regions are located in areas that can be affected by natural and industrial disasters, which can in turn trigger further damages and losses. This situation can be also described by the lack of any theoretical, methodological and scientific basis for making forecasts covering the possible destruction of assets belonging to hazardous and highly hazardous facilities and to regional infrastructure and for the recovery measures that should be taken under emergency conditions. Analysis was performed to determine the possible problems occurring at the design, construction, and restoration stages in recovery. A set of risk forecast map cards were developed, that can be applied to determine the chances of uncontrolled natural or industrial energy releases and to design the corresponding mitigation measures in the form of extreme response projects.
\end{abstract}

Keywords: emergency, mitigation, reconstruction, risk maps, extreme project.

\section{Introduction}

The modern state of research within the area of industrial objects' restoration after natural and technogenic disasters and catastrophes, characterized by large volumes of energy and power, can be characterized as fragmentary, lacking data analysis and synthesis and devoid of producing any practical value.

The goal of this research was to develop a basic theory and practical recommendations related to restoring production energy processes in the state of an emergency. In these cases, production energy is released as a result of an emergency at potentially dangerous facilities. 
Research involved analysis of the problems related to the mitigation of uncontrolled energy release consequences in extreme conditions and the development of risk forecast cards. These cards can be used to predict possible threats of uncontrolled natural and technical energy release and develop implementation models for mitigating disaster consequences and reconstruction projects. The system that was developed can be implemented for the design, construction and restoration phases of facility restoration, production energy management and control projects undertaken in extreme environments at the post-emergency stage.

\section{Nature and technology-related threats for economical and social development}

Social progress was always accompanied by threats created by human economic activities and natural disasters, often involving uncontrolled release of natural and technical energy, and causing severe economic losses [1-4].

Russian Emergency Ministry specialists assessed that almost a third part of Russian Federation subjects (namely 27) are located on territories subject to serious risks of natural and technological catastrophe. About two thirds of national production and non-production assets are located in unfavorable conditions. Statistics of recent nature and technology-related incidents, and the amount of incurred losses [5] suggest grim perspectives.

It is possible to distinguish certain non-military objects with high level of possible threats including nuclear and chemical industry installations, mining and metallurgy works, unique structures, transportation systems, major oil, gas, and product pipelines. A list of critical objects also includes dams, sewage treatment and utility facilities.

Increase in number of nature-induced and technical disasters can be partially attributed to the presence and number of critical, hazardous and extremely hazardous objects and industries that utilize substantial volumes of modern energy types (chemical, electrical, thermal, nuclear, etc). Disasters and catastrophes have become a continuously-acting development factor [6].

In general, characteristics of the forecasted natural and technogenic disasters connected with uncontrolled energy release on critical, hazardous and extremely hazardous objects can be defined by the following set of variables: damage scale, time and spatial boundaries of the disaster effects, ability to mitigate disaster consequences in timely manner and restore production, and the forecasted scope of design, construction and restoration activities necessary to resume control of the energy. It is necessary to note that the worst case scenario is to be considered whenever possible.

Energy and mass exchange processes in the real world can be defined using the objective cause-and-effect chain that includes the controlled formation of energy sources from the time and space dissipated energy array followed by the controlled utilization of energy for social and production purposes, and controlled energy conservation under conditions of controlled use. In the course of energy consumption, conservation or utilization processes, the uncontrolled 
release of energy can occur and become the reason for natural or technogenic accidents and catastrophes. These events are then followed by mitigation efforts aimed at limiting uncontrolled energy release consequences for industrial objects, adjacent infrastructure and men, followed by restoration of control over the use of energy by means of rebuilding key industrial assets, utilities and the infrastructure of adjacent territories.

Actuality of the research was determined by the lack of theoretical and methodological basis that can be used to forecast uncontrolled technogenic and natural energy releases, their consequences in form of destructing critical, hazardous, and extremely hazardous objects and adjoining infrastructure, extremely complicated and costly restoration measures required to resume control over energy and to rebuild production facilities in extreme conditions.

\section{Methodology used to restore control over production energy}

Recovery measures taken after destructive uncontrolled energy release usually cover emergency culmination phase, or search and rescue ops and immediate mitigation measures undertaken in course of accident phase I and II [4]. At the same time the necessary processes of restoring control over the released energy (post-crisis phase III) were not covered in terms of theory, methodology and approaches to implementation.

The research goal was to establish theoretical basics and recommendations for emergency restoration of control over energy that was previously released during the accident. Methodology had to cover restoration of the affected material assets, utility infrastructure, and adjacent territories.

Resulting methodology of resuming control over energy after serious accidents on critical, hazardous and extremely hazardous objects includes the following points:

- Anticipatory forecasting of possible accident scenarios involving uncontrolled energy releases.

- Classification and analysis of status and operation data for critical, hazardous, and extremely hazardous objects, performed in order to reveal problems related to mitigation of uncontrolled energy release consequences for the said objects, and the following restoration of affected facilities.

- Forecasting possible scenarios of uncontrolled energy releases using the risk maps, design of extreme project models for mitigating accident consequences, and devising sets of engineering, construction, and reconstruction activities aimed at restoration of affected production facilities.

- Developing systems for managing the abovementioned mitigation and restoration projects performed in extreme conditions on the basis of analyzing the existing theoretical approaches and methodologies.

- Justification of the necessity for top management and employees to shift from functional management ideology to the basis of project 
management and extreme project management under extreme conditions of damage recovery, resuming control over released energy, and restoration of affected objects.

Implementation of predefined projects aimed at damage recovery and restoration of control over released energy can provide time and cost savings while restoring critical, hazardous and extremely hazardous objects, and returning them into municipal, regional and national economy framework.

Industry management should be ready to face risks of emergencies and necessity to mitigate their consequences. What is even more important, management should be ready to implement design, recovery and construction activities aimed at objects restoration and return into business.

The key purpose of forecasting accidents and catastrophes involving uncontrolled energy releases is to determine possible timing of accident occurrence, damage localization and possible scale.

Engineering, construction, and reconstruction activities play the key role, and consume the top share of labor and investments required to execute extreme restoration projects aimed at restoring damaged objects, related infrastructure, and key municipal and regional infrastructure (power supply, utilities, communications, housing). In such cases it is necessary to replace traditional process and production management approaches with processes suitable for managing both investment and construction projects [7] and non-traditional extreme post-emergency restoration processes that are "compressed" in terms of time, imply enormous overnight costs, involve substantial level of uncertainty, and are localized within the confined spaces of partially or completely razed industrial buildings.

\section{Forming extreme post-emergency restoration projects}

Non-traditional extreme project as defined by DeCarlo [8] is a complex highspeed self-correcting endeavor, in course of which its participants collaborate under conditions of extreme uncertainty, constant changes and severe stress. Extreme project managers experience colossal amounts of risks, and act under pressure of circumstances and directives.

Non-traditional extreme recovery and construction projects can be characterized by instant sharp increases of labor and materials consumption, and by substantial complication of interaction among the participants in emergency conditions.

Post-emergency recovery and restoration requires formation of an extreme investment and construction program, combining traditional construction, reconstruction and turnover projects implemented before emergency in normal conditions, and a predetermined set of not-traditional extreme projects. Key to the methodology of managing this combination is to implement organizational, economic, and financial interaction among these projects, and take into account their mutual effects (fig. 1). 
In the state of emergency the tasks of project management teams and especially project managers of both traditional and extreme mitigation and recovery projects become more complicated from all points of view (such as time, resources, finances, staffing interaction of project participants, etc.) [9].

First condition of successful emergency mitigation, production restoration, and resuming control over the energy is the availability of design documents for critical, hazardous and extremely hazardous objects, construction and operation documents on different types of media, along with schedules, and network diagrams of activities performed in course of construction, reconstruction, modernization and turnover of the abovementioned objects in recent months, year, and decade.

Success of the tasks listed above depends on anticipative measures required to implement complex of traditional and non-traditional extreme investment and construction projects aimed at mitigating accident consequences and restoring the affected facilities. Measures include development of risk maps that cover

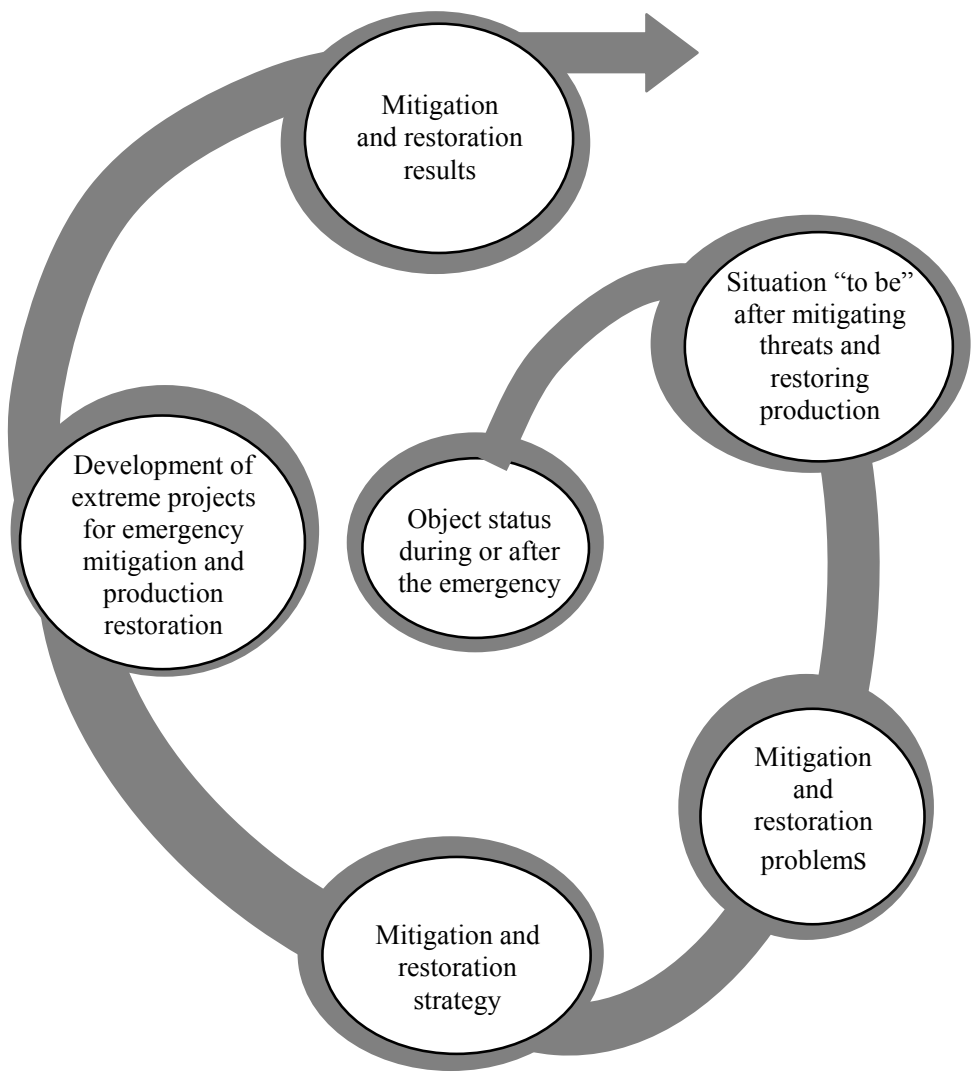

Figure 1: Methodology for mitigating uncontrolled energy release consequences and restoration of affected facilities. 
consequences of possible accident, definition of possible damage scale for the affected objects and territories, followed by project planning of the nontraditional extreme projects. These projects should cover measures necessary to restore production at the facilities affected by identified emergencies. Assessment of resources to be involved in combination of traditional and extreme clean-up and restoration projects is to be performed, along with development of schedules and network models for emergency recovery and construction activities, and assessment of the required budgets.

Set of risk maps used for forecasting includes risk maps of possible equipment failures, technogenic accidents and catastrophes and consecutive emergencies linked to locations, shops, production phases, and neighboring territories, maps of possible consequences for the defined emergencies (critical production failures, destruction of the buildings and facilities, etc.); and maps of emergency response measures (operations and activities aimed at limiting exposure, health and safety risks).

Set of forecasting maps becomes a source of data for non-traditional mitigation projects that supplement traditional efforts aimed at resuming control over the energy, restoring affected facilities, infrastructure, and adjacent territories.

Four-level system of risk maps was provided (fig. 2). This system includes multiple parameters of the occurring incidents, including necessary damage statistics, state of destroyed assents and infrastructure, planning criteria for the extreme projects.

\begin{tabular}{|c|c|c|c|}
\hline Step 1 & Step 2 & Step 3 & Step 4 \\
\hline $\begin{array}{l}\text { Development of } \\
\text { Level I risk maps } \\
\text { describing } \\
\text { emergencies in terms } \\
\text { of localization, } \\
\text { duration and damage, } \\
\text { and forecasting } \\
\text { probability of } \\
\text { consequences }\end{array}$ & $\begin{array}{l}\text { Development of } \\
\text { Level II risk maps } \\
\text { describing } \\
\text { emergency } \\
\text { consequences in } \\
\text { terms of location, } \\
\text { volume, threats and } \\
\text { hazard level. } \\
\text { Forecasting } \\
\text { required mitigation } \\
\text { measures }\end{array}$ & $\begin{array}{l}\text { Development of } \\
\text { Level III risk } \\
\text { maps describing } \\
\text { mitigation } \\
\text { measures in terms } \\
\text { of location, } \\
\text { volume, and } \\
\text { considering } \\
\text { hazards and safety } \\
\text { factors. } \\
\text { Forecasting } \\
\text { response measures } \\
\text { taken at different } \\
\text { levels and by } \\
\text { various parties }\end{array}$ & $\begin{array}{l}\text { Development } \\
\text { of Level III } \\
\text { risk maps } \\
\text { describing } \\
\text { possible } \\
\text { emergency } \\
\text { interactions of } \\
\text { the mitigation } \\
\text { parties. } \\
\text { Forecasting } \\
\text { parameters of } \\
\text { resulting } \\
\text { projects }\end{array}$ \\
\hline
\end{tabular}

Figure 2: System of risk maps for emergency mitigation, and restoration of critical, hazardous and extremely hazardous objects. 
Research results allowed creating the set of practical measures ranging from production halt to mitigation, recovery and restoration of critical, hazardous and extremely hazardous objects damaged during the uncontrolled energy release.

The set of function was determined that is implemented in course of managing the combination of traditional and non-traditional investment and construction mitigation and restoration projects.

Suggested methodology has a specific project life cycle featuring parallel execution of both activities within project phases (concept development, design, construction, etc.), and of the phases themselves.

Comparing generalized life cycle profiles of a traditional and extreme project (figs. 3 and 4) demonstrates sharp front-end resource demand increase for the latter $\left(\mathrm{P}_{\max }^{\mathrm{ep}}\right)$ compared with the former $\left(\mathrm{P}_{\max }^{\mathrm{tp}}\right)$. That is due to the fact of combining activities and phases within the extreme project where feasibility study, design and investment phase occur almost simultaneously.

It is clear that emergency response and restoration efforts require both strategic and tactical implementation plans for combination of the recombined projects developed in advance, and supplemented by schedules and estimates for project life cycle phases, objects and construction activity types. These plans may feature combined activities within the phases or lack certain activities for the objective reasons. At the same time key goal of the main activities within the phase is to mitigate negative effects of an emergency, and restore object functioning.

Possible combinations of activities within the phases or phases themselves can depend on the set of mitigation and restoration conditions, and imposed completion dates.

It was found that in order to limit duration for projects combination it is better to implement ideology of combining both activities within the phases, ad phases of the "reversed" project cycle.

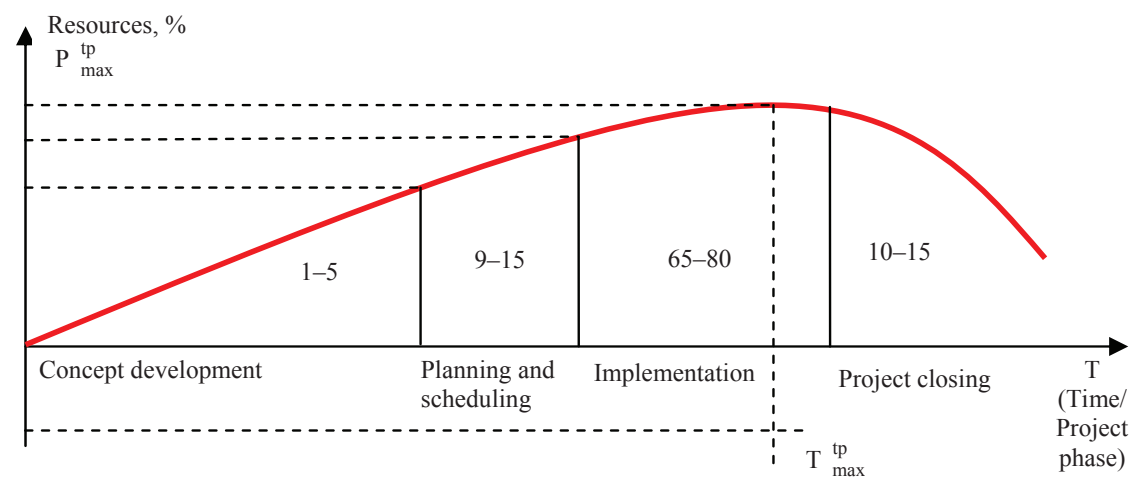

Figure 3: Traditional investment project life cycle [7]. 


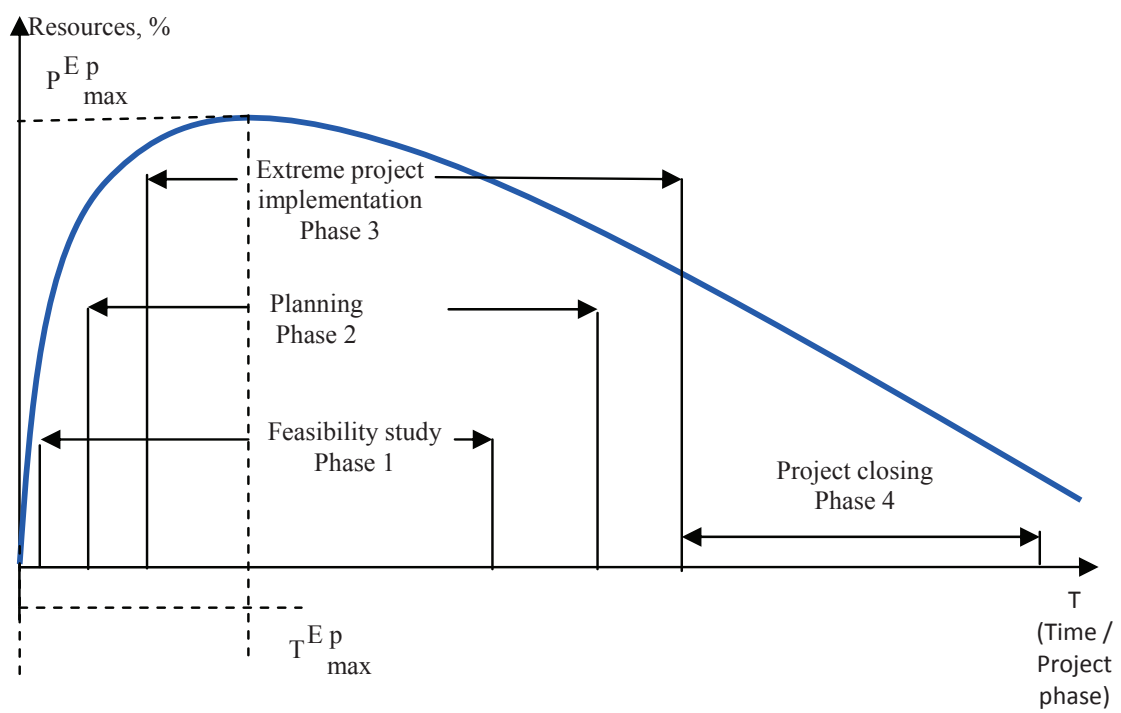

Figure 4: "Reversed" life cycle of an extreme project.

\section{Conclusion}

Combination of both phases and activities within the phases for the combination of traditional and extreme projects allows the most efficient implementation of post-incident mitigation and object restoration measures.

Rear emergences, however, may require even further "crushing" in terms of combining activities and phases for the abovementioned project combination.

\section{References}

[1] Tatarkin, A.N. et al. Status of Russian and Ural regional energy safety and the ways of threats mitigation [in Russian] // Proc. of regional conference on development of regional economy: innovations, investments, management. Institute of economics, Ural division of RAS: Ekaterinburg, 2001.

[2] Kochetkov, K.E. \& Zabegaev A.V. (eds.) Incidents and catastrophes: Prevention and Mitigation. Vol. 1 [in Russian], ASV: Moscow, 1995.

[3] Akimov, V. Emergencies: danger assessment [in Russian]// Strahovoe delo, 1, pp. 38-45, 1998.

[4] Russian Federation: Federal Law No.116-FZ on industrial safety of hazardous production sites (amended by Federal Law No.22-FZ of March 04 2013) // Rossiyskaya Gazeta, issue № 48 (6024), March 06 2013. 
[5] Kuklin, A.A. \& Myzin, A.L. (eds.) Industrial and regional problems of forming energy security [in Russian]. Publishing house of the Ural division of RAS: Ekaterinburg, 2008.

[6] Tschegolev, V. Management in a state of emergency: experience, suggestions, and perspectives [in Russian] // Grazhdanskaya zaschita, 11, pp. 40-41, 2000.

[7] Mazur, I.I., Shapiro, V.D. et al. Project Management: A Professional Guide [in Russian]. Vyshaya Shkola: Moscow, 2001.

[8] DeCarlo, Douglas. eXtreme Project Management: Using Leadership, Principles, and Tools to Deliver Value in the Face of Volatility [Russian Edition] p. m. Office: Moscow, 2007. 500 p.

[9] Egorova, A.N. Managing construction and recovery in extremely complex conditions [in Russian]// Ekonomika i upravlenie, 1, pp. 87-90, 2006.

[10] Verstov, V.V. \& Egorov, A.N. Key ways of technology improvement for emergency mitigation [in Russian] // Montazhniye spetsialnye stroitelnye raboty, 8, pp. 2-4, 2003. 